Portland State University

PDXScholar

7-1-2008

\title{
Production, Oxidation, and Emissions of Methane from Rice Fields in China
}

\author{
M. A. K. Khalil \\ Portland State University, aslamk@pdx.edu \\ Martha J. Shearer \\ Portland State University \\ R. A. Rasmussen \\ Oregon Graduate Institute \\ Chang-Lin Duan \\ Institute of Mountain Disasters and the Environment \\ Lixin Ren \\ Chinese Academy of Sciences
}

Follow this and additional works at: https://pdxscholar.library.pdx.edu/phy_fac

Part of the Physics Commons

Let us know how access to this document benefits you.

\section{Citation Details}

Khalil, M. A. K., M. J. Shearer, R. A. Rasmussen, C. Duan, and L. Ren (2008), Production, oxidation, and emissions of methane from rice fields in China, J. Geophys. Res., 113, G00A04.

This Article is brought to you for free and open access. It has been accepted for inclusion in Physics Faculty Publications and Presentations by an authorized administrator of PDXScholar. Please contact us if we can make this document more accessible: pdxscholar@pdx.edu. 


\title{
Production, oxidation, and emissions of methane from rice fields in China
}

\author{
M. A. K. Khalil, ${ }^{1}$ M. J. Shearer, ${ }^{2}$ R. A. Rasmussen, ${ }^{3}$ Duan Changlin, ${ }^{4}$ and Ren Lixin ${ }^{5}$ \\ Received 3 April 2007; revised 10 October 2007; accepted 5 November 2007; published 22 July 2008.
}

[1] Detailed field studies of methane emissions from rice fields show that when nitrogen fertilizers are used with intermittent irrigation the seasonal average flux is about $3 \mathrm{mg} / \mathrm{m}^{2} / \mathrm{hr}$. When continuous flooding and organic material is added to the same fields, the emissions rise to nearly $30 \mathrm{mg} / \mathrm{m}^{2} / \mathrm{hr}$. Production rates measured during the two years when both organic material and water were applied to these fields were found to be 60 and $90 \mathrm{mg} / \mathrm{m}^{2} / \mathrm{hr}$ in consecutive years. The fraction oxidized is calculated to be about $80 \%$ one year and $43 \%$ the next year. The results suggest that high organic fertilizer increases production, but may affect the emissions more by reducing oxidation.

The data show that seasonally averaged emissions vary by up to factor of 2 among adjacent fields but the variability of production is only about $20 \%$. Information obtained from the farmers suggests that there is a trend towards less use of organic manure as nitrogen fertilizers have become available and the occurrence of intermittent flooding has increased for various reasons. These conditions have likely led to decreasing emissions of methane from rice fields in China in the recent decades.

Citation: Khalil, M. A. K., M. J. Shearer, R. A. Rasmussen, C. L. Duan, and L. X. Ren (2008), Production, oxidation, and emissions of methane from rice fields in China, J. Geophys. Res., 113, G00A04, doi:10.1029/2007JG000461.

\section{Introduction}

[2] Methane is one of the gases that can cause global warming in the future and rice fields are known to be a major anthropogenic source. Indeed the increase of rice agriculture to support a growing population is regarded as one of the reasons that there is now more than twice as much methane in the atmosphere compared to a century ago. The early studies focused on measuring methane emissions from rice fields but came up with a wide range of seasonally averaged emission rates under seemingly similar environmental conditions, ranging from nearly no emissions to $40 \mathrm{mg} / \mathrm{m}^{2} / \mathrm{hr}$. In time, studies pointed to a number of environmental factors and agricultural practices that affect emissions. The factors that seemed to have the most influence in practical rice agriculture are the amount of organic matter applied to the fields and the management of water. Other factors also affect methane emissions and may in some cases be more important than these, but probably not on a country or global scale. The organic material is in

\footnotetext{
${ }^{1}$ Department of Physics, Portland State University, Portland, Oregon, USA.

${ }^{2}$ Environmental Science and Resources Program, Portland State University, Portland, Oregon, USA.

${ }^{3}$ Department of Environmental and Biomolecular Systems, Oregon Graduate Institute, Oregon Health and Sciences University, Beaverton, Oregon, USA.

${ }^{4}$ Institute of Mountain Disasters and the Environment, Chengdu, Sichuan, China.

${ }^{5}$ Institute of Atmospheric Physics, Chinese Academy of Sciences, Beijing, China.
}

Copyright 2008 by the American Geophysical Union. 0148-0227/08/2007JG000461\$09.00 the form of applied fertilizer, such as composted material, sludge from biogas pits or from residues of previous crops. Water is generally supplied by irrigation or rain. In recent times there has been an increasing shortage of water as it is used more and more for other purposes [see, e.g., Barker et al., 2004]. Experiments show that if organic material is replaced with nitrogen fertilizers, or when the rice fields are intermittently flooded, then the methane emissions drop dramatically [see Shearer and Khalil, 1993, 2000, and references therein].

[3] During the four years between 1996 and 1999 we conducted holistic field studies of methane emissions from rice fields around Jinsha, a small agricultural village in Sichuan Province of China. Although at first we studied the fields under the normal agricultural practices of the region, in the later years we intervened with continuous flooding and organic amendments to study the effects on methane emissions. We also measured the production rate of methane in the soil below the rice paddies to determine the connection between production, oxidation and emission. The results of this study are discussed here, and the data can be obtained from Data Sets S1-S4 (available as auxiliary material) for further use by the readers. ${ }^{1}$

[4] In the remaining sections we will describe the experiments carried out in up to six different but adjacent fields with three replicate plots in each field. We will discuss the seasonal variation of the methane emissions from these rice fields and the spatial variability as measured by the replicates. We will show the progression of low emissions when

\footnotetext{
${ }^{1}$ Auxiliary materials are available at ftp://ftp.agu.org/apend/jg/ 2007jg000461.
} 
nitrogen fertilizers were used to progressively higher emissions as both continuous flooding and an abundance of organic fertilizers were supplied to the same fields. The production measurements will show the vertical and temporal evolution of the processes in the soils. Finally we will show that under conditions that favor the highest fluxes, reduced oxidation may have a greater effect on emissions than increased production. At the end of this work, we have increased our knowledge of the mechanics of methane production from rice fields and the theoretical understanding of the processes.

\section{Fields and Field Experiments}

\subsection{Field and Site Characteristics}

[5] Jinsha is a small village located about $30 \mathrm{~km}$ west of the major city of Chengdu in the heart of Sichuan Province $\left(30.55^{\circ} \mathrm{N}, 103.84^{\circ} \mathrm{E}\right)$. Rice has been a major crop in this area for hundreds of years. We selected six fields near the village for our experiments, all of which were owned, planted and managed by local farmers. In each field three plots were selected for sampling. Not all fields were used every year due to monetary and logistical constraints. We paid a fee for the use of the fields and for the rental of space in one of the farms to operate our gas chromatograph to measure methane. The fields were numbered 1 to 6 and the areas in hectares were noted to be $0.044,0.065,0.058$, $0.089,0.07$ and 0.042 respectively. The time between transplanting of rice in the fields to harvest was 98, 98, 111 and 102 days respectively for the four years 1996-1999.

[6] During the first two years, according to our information, there was little use of organic fertilizer and the fields were only intermittently flooded. The local farmers had, some years ago, shifted to using commercial nitrogen fertilizers. During the subsequent years (1998 and 1999) we asked for the fields to be flooded and supplied with organic amendments, which was done reluctantly by the farmers. Upon examination of the field notes, site logs and various written communications we have concluded that a quantitative record of how much organic fertilizer, if any, was applied to which field, cannot be accurately reconstructed for the first two years. Records are more reliable for the last two years when organic fertilizer was applied according to our requests, but in 1999 wheat straw from the previous crop was incorporated into the soil because new regulations limited the burning of the stubble. Thus the exact amount of organic material in the fields during the last year is not known, except that it was probably more than in any previous years. Records for nitrogen fertilizer applications are more reliable. Urea and ammonium hydrogen carbonate $\left(\mathrm{NH}_{4} \mathrm{HCO}_{3}\right)$ and compound $\mathrm{NPK}$ were the main fertilizers used, but the flux of methane does not appear to depend on these, so the amounts and timing of these applications are included in the auxiliary material and not discussed further here.

[7] The water levels were measured when the flux samples were taken and thus constitute a direct measure of the flooding regimes during the course of our experiments. In the first two years there was generally intermittent flooding, and particularly in 1997, when there was a drought reported, so rain supplied water was also limited. In the two later years, we asked for the fields to be continuously flooded, and they mostly were. For our experiments therefore, we conclude that there was intermittent flooding and low levels of organic fertilizers in the fields for the first two years (1996 and 1997) and there was more water and fertilizer in the fields in the next two years (1998 and 1999) culminating in continuously flooded conditions and abundant supply of organic matter during the last year.

[8] In the first two years the soil chemical composition was analyzed by the Chinese scientists using methods standardized by the Chinese Ecosystems Research Network. The results as reported to us are included in the auxiliary material. The measurements showed that for the 15 plots in 5 fields studied in 1996 the elements and organic matter were in the following percentages by weight where the main number is the average for all the plots and the range is the minimum and maximum measured: Organic Matter: 3.2 (2.8-3.5), N: 0.14 (0.09-0.14), P: 0.08 (0.07-0.09), Ca: $0.6(0.4-0.7)$ and $\mathrm{Mg}: 1.1(0.9-1.6)$. The $\mathrm{pH}$ was 6.3 (5.67.9). In 1997, the soil chemistry was measured three times during the growing season. The averages for all 18 plots in the 6 fields and growing season were: Organic Matter: 3.0 (2.7-3.2), N: 0.18 (0.17-0.19), P: 0.1 (0.08-0.12), Ca: 1.2 (1.0-1.4) and $\mathrm{Mg}: 1.1(1.0-2.0)$ and the $\mathrm{pH}$ was 6.9 (6.6$7.8)$. No trends were seen in the organic matter content during the year. For both the years there were modest correlations of about $0.5(\mathrm{p} \times 0.01)$ between the methane flux and the organic matter content; for the other variables the correlations were generally smaller.

\subsection{Measurements Taken}

[9] Four classes of measurements were taken throughout the growing season: The emissions or fluxes of methane, production, plant growth dynamics and environmental conditions. The flux measurements were taken by chamber methods described in detail previously by Khalil et al. [1998a]. The essential features of the method are that a base of approximately $1.5 \mathrm{~m} \times 1.5 \mathrm{~m}$ is installed in the field before the rice is planted. We consider this the sampling plot. There are always three plots in each field to obtain replicate samples for otherwise assumed homogeneous conditions. The base consists of a gutter, of sufficient width and dimensions to accommodate the frame of a rectangular chamber. The base creates a rigid platform for placing the chambers and the water filled gutter serves to seal the chamber from outside air and mud in the field. If the fields are not inundated, the gutter is filled with water to create the seal. The sealed chamber is about $1.4 \mathrm{~m} \times 1.4 \mathrm{~m} \times 1 \mathrm{~m}$ tall, made of PVC piping frame and draped with 0.1 mil plastic sheeting. There is a small battery operated fan inside near the top of the chamber to mix the air and a sampling port consisting of a nut with septum into which the needle of a plastic or glass syringe can be inserted to collect the sample. Before the rice was planted, boardwalks were installed from the edge of the field to the location of the plots allowing access to portions of the field away from the edges. To measure the flux the chamber is placed gently on the groove in the frame. Four samples are drawn at 5 minute intervals using syringes. These are analyzed using a field GowMac gas chromatograph at a later time but as soon as possible after the sample is collected (see Khalil et al. [1998a] for details). The buildup of methane is a direct measure of the 
emissions from the plot and is calculated using a mass balance at the measured temperature in the chambers. During the years of this experiment from 1996 to 1999 measurements were taken in 5, 6, 5 and 3 fields each with 3 replicate plots. The sampling frequency during the first two years emphasized more days per growing season and consisted of pairs of days. On one day samples were collected in the afternoon and on the next, samples were collected in the morning. This gave us what may be considered a diurnal measure of the flux for this time. Then there was a break of 2 days and the cycle repeated. In the last 2 years we sampled twice a day: morning and afternoon, once again to measure the "diurnal" effect and the gap between days sampled was extended to 3 days. The afternoon soil temperatures are almost always higher, but there are no other changes from the morning of the same day or the day before.

[10] The measurements of flux are validated by two criteria. The first is to consider the linearity of the accumulation so that the correlation coefficient between the sampling time and the chamber concentration for the four measurements is greater than or equal to $0.95\left(\mathrm{r}^{2}>0.9\right)$. If it is less than that, the data are individually examined and retained if a correctable error is found. Usually a lower correlation arises from one of three sampling problems: First when there really is no flux and the concentrations in the chamber fluctuate near ambient levels but do not systematically increase; second, if the chamber or the rice plants are accidentally shaken enough to disturb the soil and release large amounts of methane by agitation, and finally, due to natural bubbling that may occur sporadically. In earlier studies, characteristic profiles of these conditions were examined in detail [Khalil et al., 1998a]. The second criteria is to consider the other plots in the same field and for the same sampling time. If the flux from one plot is widely inconsistent with the fluxes from the other two, then it is discarded (generally 3 or more standard deviations higher). The purpose of the triplicate measurement is to insure that the measurement is representative of the field and not just the one $1.5 \mathrm{~m} \times 1.5 \mathrm{~m}$ plot. About $8 \%$ of the measurements did not meet these criteria. The problems are usually more frequent when the plants have grown because then the probability of large fluxes due to disturbances is much higher. Since our sampling frequency is not very high, each day of flux measurement is considered representative of not only that day, but the days until the next sampling. Therefore, occasional large fluxes from a few plots, even if these are real, are justifiably eliminated as these would not be valid for the several days that each sample is assumed to represent. The number of flux measurements taken were $1087,934,978$ and 524 for the years $1996-1999$ or a total of slightly over 3,500 which represents more than 10,000 individual concentration measurements.

[11] Production measurements were conducted throughout the growing season but at a lower frequency because of monetary and logistical constraints. We used a sludge auger with a $7.5 \mathrm{~cm}$ diameter plastic liner to extract a soil core down to the base of the tilled layer, which is about 15$20 \mathrm{~cm}$. Samples of soil are then taken from between the plants and from various depths about $2.5 \mathrm{~cm}$ apart, which represents the separation of the sampling holes in the plastic liner. Each sample consisted of about $10 \mathrm{~cm}^{3}$ of wet soil.
The sample was placed in a glass flask and the flask was flushed with nitrogen to keep it anaerobic. Paddy water was added to emulsify the mud sample. Samples of gas from the headspace were withdrawn from the flask each hour or every two hours for 4-20 hrs. The gas withdrawn was replaced with nitrogen and the samples analyzed to determine methane concentrations. The production rate was calculated by regression over times starting with the first measurement to a several hours later when the accumulation was linear. Recent work using isotopes and microbiological techniques point to some discrepancies with the results obtained from incubation studies such as ours [see, e.g., Eller and Frenzel, 2001; Krüger et al., 2002]. Our results are do not address this issue, but are consistent with similar work.

[12] The plant growth dynamics data consist of records of plant height, number of tillers and the dates of the major events in the life cycle of the crop: seeding, transplanting into the field, tillering, flowering, and harvest. These data are included in the auxiliary material accompanying this paper, but are not used extensively in further discussions here.

[13] Finally, a number of environmental variables are measured, the most important being water levels and soil temperature at $5 \mathrm{~cm}$ depth. In addition, measurements were taken of the air temperature, wind speed and sky conditions reflecting cloudiness and rain. $\mathrm{pH}$ and redox potential were also measured, but due to instrument malfunctions, only a few reliable redox data were obtained which are included in the auxiliary material. It was established in earlier studies that methanogenesis is initiated when the redox potential (Eh) has fallen below about $-150 \mathrm{mV}$ [Masscheleyn et al., 1993]. For the aims of this study however, the actual values of Eh were not important.

\section{Emissions of Methane}

[14] The standard theory, in brief, is that methane is produced by methanogenic bacteria in the deeper layers of the tilled top soil in the rice field [see, e.g., Boone, 2000; Neue and Roger, 2000]. The depth of this layer was measured in our present studies and was about $15-20 \mathrm{~cm}$. Methane is then transported to the upper layers through the pore water by concentration gradients, by bubbles or by gradient driven flux into the paddy water. Of these, the transport through the plant has been found to be the dominant pathway when the whole season flux is calculated. The root zone in the upper layers near the surface or the roots themselves, harbor methanotrophic bacteria that consume methane. The amount that is not consumed can diffuse through the root and from there it is rapidly transported to the aerenchyma through which it escapes to the atmosphere. Since the aerenchyma do not open or close, the flux is not affected by sunlight or most other diurnal variations, except possibly the soil temperature [Nouchi et al., 1990; Denier van der Gon and van Breemen, 1993; Aulakh et al., 2000a, 2000b].

[15] The bubbles are a complicating factor in the understanding of the net flux during the season, but previous studies have shown that the emissions by this pathway are a small fraction of the seasonal total [Holzapfel-Pschorn et al., 1986; Schütz et al., 1989; Chanton and Dacey, 1991]. In 

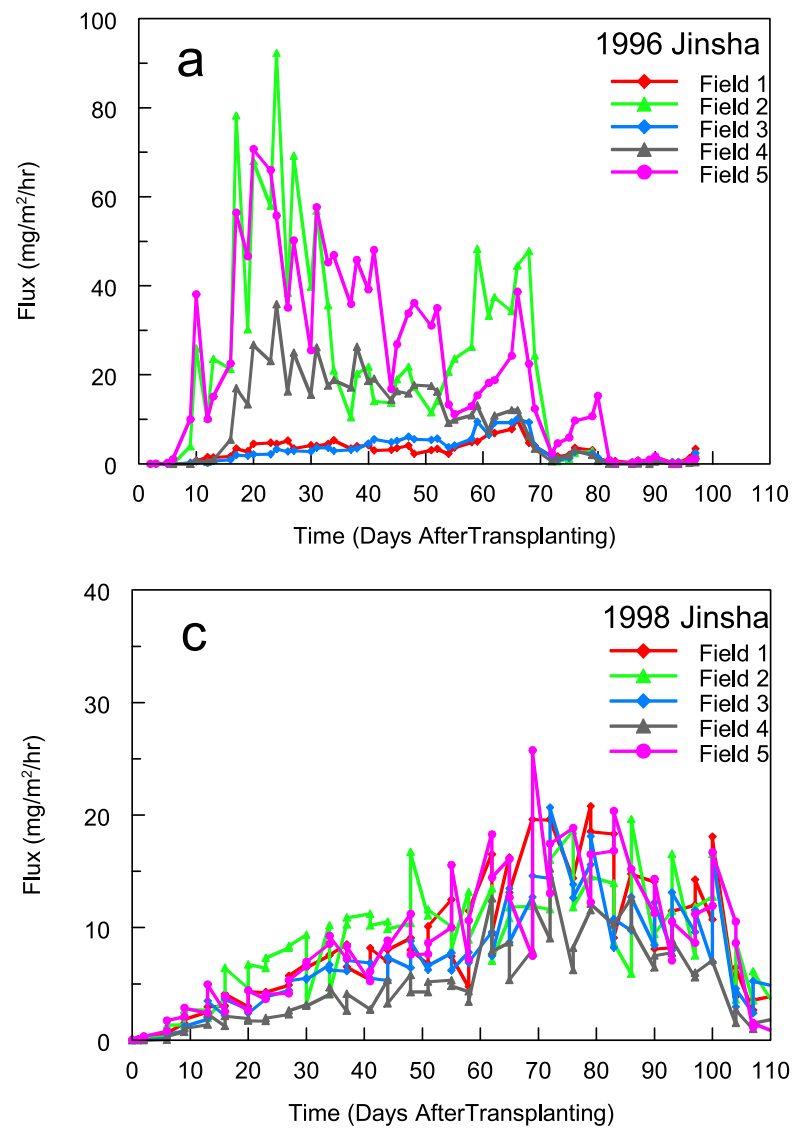
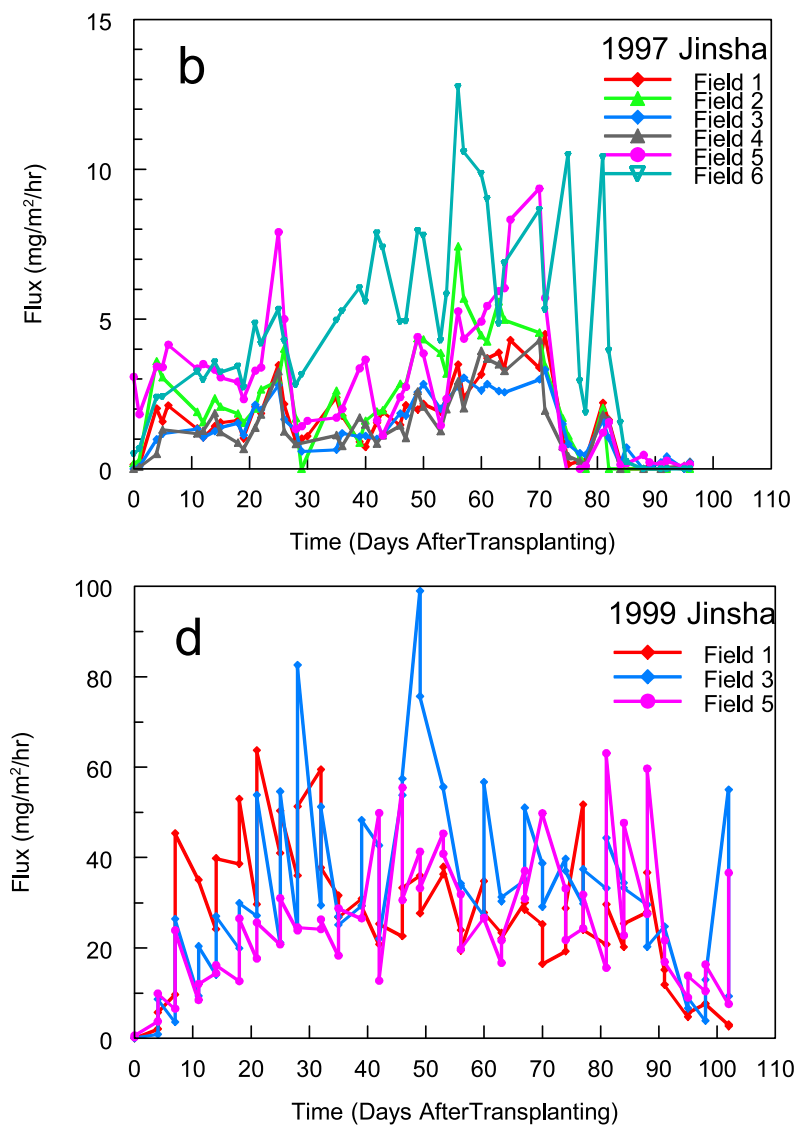

Figure 1. Methane emissions from rice fields during the growing seasons at Jinsha in Sichuan Province of China.

the flux measurements, the effect of bubbles is included only if it occurs during the sampling process as discussed in the previous section. In these experiments as in others, we sampled plots in the rice fields but with no plants inside to see the effect of plants on the flux. For the present experiments such measurements were taken only during 1997, in which the "no plant plots" released very little methane as will be shown later.

[16] We can consider a mass balance consistent with the measurements taken in this experiment to link the production, oxidation and flux as described by the standard theory. Consider the rice field to be made up of thousands of contiguous plots. Each plot, which can be taken to be size of our chamber, has an area on the top of the field and a soil depth $\delta$ that goes to the bottom of the plowed layer (15$20 \mathrm{~cm}$ ). We can express the production, oxidation and transport in terms of mass per unit area to be readily comparable with the measured fluxes, the standard units for which are $\mathrm{mg} / \mathrm{m}^{2} / \mathrm{hr}$. The mass balance is:

$$
\mathrm{dC} \delta / \mathrm{dt}=\mathrm{P}-\Phi-\mathrm{Ox}
$$

Here $\mathrm{C}\left(\mathrm{mg} / \mathrm{m}^{3}\right)$ is the amount of methane in the soil, mostly in the pore water (not measured here) and $\delta(\mathrm{m})$ is the depth of the plowed layer assumed to be constant during the growing season, $\mathrm{P}\left(\mathrm{mg} / \mathrm{m}^{2}-\mathrm{hr}\right)$ is the production of methane in this layer integrated over the depth $\delta, \Phi$ is the flux and $\mathrm{Ox}$ is the oxidation rate in the soil of the plot (both in $\mathrm{mg}$ / $\mathrm{m}^{2}$-hr). The production is normally measured as $\mathrm{P}_{\mathrm{o}}(\mathrm{z})$ in $\mathrm{mg} / \mathrm{m}^{3} / \mathrm{hr}$ at various depths $\mathrm{z}$, so that $\mathrm{P}=\left\langle\mathrm{P}_{\mathrm{o}}\right\rangle \delta$ where $\left\langle\mathrm{P}_{\mathrm{o}}\right\rangle$ is the production rate averaged over depth. All of these quantities change during the growing season and may have substantial spatial variability. These features will be discussed in detail later for the observed production and emission rates, and the calculated values of oxidation.

[17] It is of considerable interest to know the oxidation rate, since past studies have shown that it is as high as $90 \%$ [Holzapfel-Pschorn et al., 1986; Schütz et al., 1989], to below 5\% [Krüger et al., 2001]. If the flux is the small difference between production and oxidation, then oxidation may well be the controlling factor that leads to the widely varying emissions observed under seemingly similar environmental conditions. The fraction of methane oxidized is usually determined as $\mathrm{f}=\mathrm{Ox} / \mathrm{P}$, which from equation (1), in terms of measured quantities such as flux and production is:

$$
\mathrm{f}=[1-\Phi / \mathrm{P}]-[(\mathrm{dC} \delta / \mathrm{dt}) / \mathrm{P}]
$$

Since in most studies, including ours, the pore water concentration (C) is not measured, the second term on the right hand side complicates the calculation of instantaneous value of the oxidized fraction. With this context in mind, we are ready to discuss our results.

[18] The temporal changes in the flux during the growing season are shown in Figure 1. The main characteristic is low emission rates at the beginning of the growing season, rising 


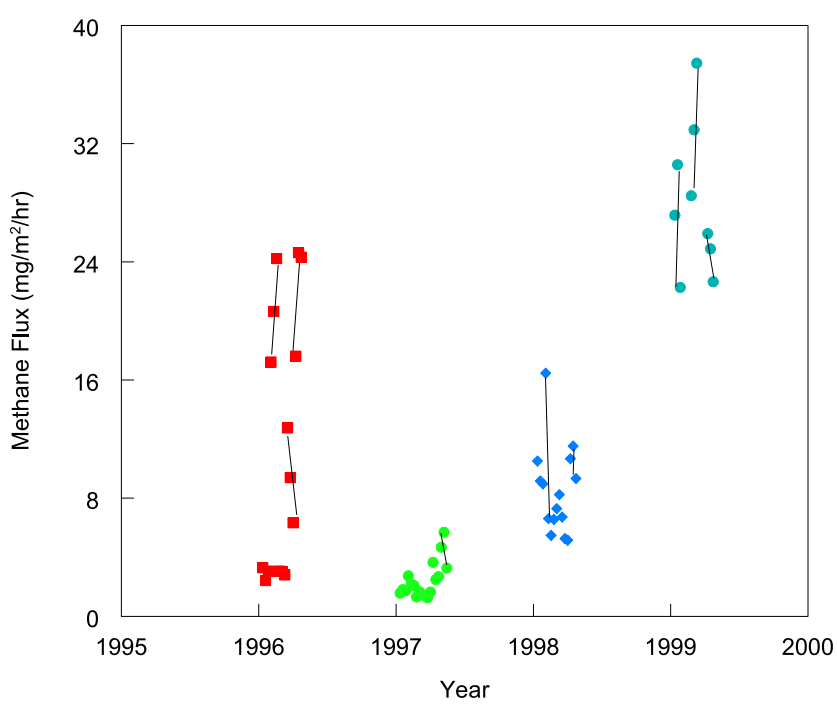

Figure 2. Methane emissions from rice fields in Jinsha, Sichuan. Each point represents the seasonal average emission rate over about 100 days of the growing season from each of three plots in up to six fields near each other. The groupings of three points each show the variability of plots in the same field, while the overall differences between groups of the three points shows variability among fields for each year. For each year the data are separated from each other by a slight offset on the $\mathrm{x}$-axis to group each field and make the variability within and across fields more visible.

to peak emissions as the plants tiller and grow and finally a sharp drop after seeding. This is also a time when the fields are often no longer inundated. In between the low emission phases, there are a number of known factors that affect emissions in this and all other previous studies. These factors include water levels, fertilizer applications and soil temperatures, to be discussed later.

[19] Although the seasonal cycle of emissions is essential for the understanding of the processes that cause methane to be released from the rice fields, for other uses, such as estimating regional and global annual emissions from rice fields, the seasonally integrated average emission rate is most useful. This is shown in Figure 2. The integrated average flux is obtained by the following formula that is applied to all the sampled variables (V) of interest:

$$
\begin{aligned}
\langle\mathrm{V}\rangle & =1 / \mathrm{T} \int_{0}^{\mathrm{T}} \mathrm{V} \mathrm{dt} \\
& \approx\left\{\sum_{\mathrm{i}=1}^{\mathrm{n}}\left[\mathrm{V}\left(\mathrm{t}_{\mathrm{i}}+\delta \mathrm{t}_{\mathrm{i}}\right)+\mathrm{V}\left(\mathrm{t}_{\mathrm{i}}\right)\right]\left(1 / 2 \delta \mathrm{t}_{\mathrm{i}}\right)\right\} / \Sigma \delta \mathrm{t}_{\mathrm{i}}
\end{aligned}
$$

where $t_{i}$ for $i=1 \ldots n$ are the times when samples are taken and $\delta \mathrm{t}_{\mathrm{i}}$ is the times between sampling. $\mathrm{V}=\Phi$ for calculating the average flux shown in Figure 2.

[20] We consider first the inter-annual changes of emissions. These are not due to the natural variability of emissions from this area, but rather to changes in agricultural practices, some of which were made as part of this experiment. In the first year, two of the fields (1 and 3) and all the fields in the second year (1997), are consistent with the emissions that may be expected from the prevailing conditions of low organic inputs and intermittent flooding, with seasonally averaged emission rates of about $3 \mathrm{mg} / \mathrm{m}^{2} / \mathrm{hr}$. In the first year however, three of the five fields had high emission rates that were quite puzzling when we first calculated them and remain so even now. Nonetheless, the emissions from the plots within the fields are consistent with each other, and no other source of error was identified, so we have included them here. We think that rice straw and residues from the previous year's crop were left in these fields and not burned as was done in the other fields. Since this was before our experiments started, no record was made. The emissions from these high production fields are quite similar to those seen in the last year when crop residues are known to have been left in the fields. We observed that the background concentrations of methane measured at the edges of each field were generally low during 1997 which would suggest low fluxes from all the fields.

[21] The observations of low emissions, especially in 1997 led us to design experiments to see if these were indeed due to the major factors that have been identified to cause high emission rates at other locations, namely addition of organic amendments and continuous flooding. This matter was particularly important to our studies since the sites at Jinsha were only about $100 \mathrm{~km}$ north of Tuzu where we had done experiments over a number of years and had consistently found seasonally averaged fluxes of about $30 \mathrm{mg} / \mathrm{m}^{2} / \mathrm{hr}$, or 10 times higher than what we saw in Jinsha in 1997 (and 1996 with the caveats about the other 3 fields). In 1998 organic matter was added to the fields and every attempt was made to keep the fields flooded, but this was not completely successful. In the final year (1999) the fields were continuously flooded and there was an abundance of organic material applied to the fields, mostly because wheat straw from previous crops had to be plowed into the fields rather than burned. We see that under normal agricultural practices of intermittent flooding and applications of mostly nitrogen fertilizers the emissions are low, at about $3 \mathrm{mg} / \mathrm{m}^{2} / \mathrm{hr}$ in the first 2 years. With the addition of organic fertilizer and more water, the emissions go up to $9 \mathrm{mg} / \mathrm{m}^{2} / \mathrm{hr}$ and when both water and organic material is present in large quantities the fluxes are about $30 \mathrm{mg} / \mathrm{m}^{2} / \mathrm{hr}$, which are consistent with the results from nearby Tuzu where the same agricultural conditions prevail. Except for the high emitting fields in 1996, this is a consistent picture of how water and organic amendments can lead to a 10 fold increase in emissions from the same fields and under otherwise similar conditions. Unfortunately we must leave this issue as a qualitative explanation. We are not able to determine the important roles that the amount and timing of organic fertilizer applications play since, due to logistical problems, such information was not accurately recorded. On the other hand, we have direct measurements of the water levels when the flux samples were taken, which we examine in more detail next.

[22] The effect of intermittent flooding on methane emissions is quite complicated. The reduction of emissions depends on the timing, frequency and duration of dry conditions. During these periods the soil is at least moist 


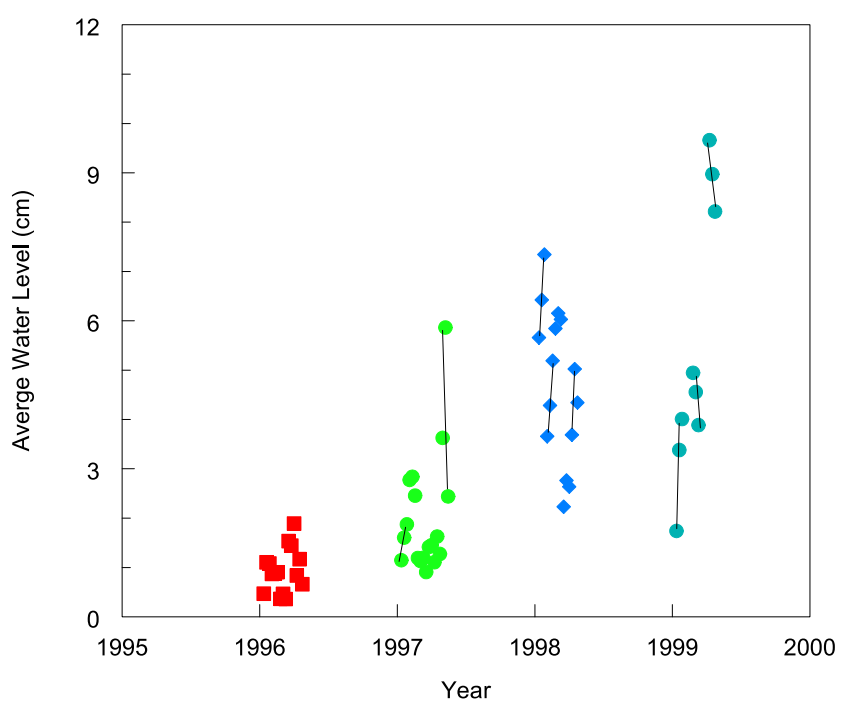

Figure 3. Integrated average water levels measured in the rice fields at the same time that flux samples were taken.

and may be saturated, but there is no standing water. These conditions arise either if the fields are drained, or often when the water that has evaporated is not replaced, a common occurrence in some rice growing areas towards the later phases of rice growth when standing water no longer serves to prevent weeds. If the fields dry out during the middle of the growing season, the reduction of methane emissions is greater because at that time emission rates are usually high. Similarly it takes time for the lack of standing water to affect the production processes well below the surface. A longer duration therefore has a greater impact on methane emissions than a shorter one. Finally the frequency is also significant since if water is put back but does not remain long in the fields, there is not enough time for the methane production to build up before it is disrupted again. These factors present a myriad possibilities for how intermittent flooding could affect methane emissions. Fortunately only a few characteristic cases actually occur in practice.

[23] By using equation (3) we can calculate the average water levels during the growing season as an indicator of flooding but it does not distinguish between widely differing cases of the factors such as the frequency and duration of drying mentioned earlier. The integrated average water levels according to equation (3) are shown in Figure 3. A better index of intermittent flooding, as it affects methane emissions, is:

$$
\mathrm{I}=-(\mathrm{ND} / \mathrm{L})
$$

Here $\mathrm{N}$ is the number of dry events, $\mathrm{D}$ is the total duration of dry days and $\mathrm{L}$ is the length of the growing season. This index is still very simple and does not represent all the complexities of the process by which intermittent flooding affects methane, but we will use it here. It is zero for continuously flooded fields $(\mathrm{N}=0)$ and goes to negative numbers for dryer conditions. In Figure 4 we show the flux as a function of the dryness index for each plot and each year. Here and in subsequent figures we have excluded the 3 anomalous fields of 1996 as these do not follow any pattern consistent with the remaining fields for the same year or the three subsequent years of measurements and hence obscure the relationships that are seen in the complete data set. It is easy however, to visualize their positions on the figures.

[24] One reason for including the results for the individual plots is to show that the measured water levels were not the same at different places even in the same field, and there were differences also in the water levels among fields in the same year. This issue arose mostly in 1998 (3rd year), when we had asked for continuously flooded fields, but the farmers were not able to deliver enough water to keep the levels high in all fields for the duration of the growing season. For many of the plots in the last 2 years the index is high representing mostly flooded conditions, yet the fluxes are higher in the last year (1999). This we attribute to the saturated organic carbon supply in the final year as discussed earlier. It is noteworthy that in 1997 the actual integrated average water level was higher than in 1996 ( $2 \mathrm{~cm}$ compared with $1 \mathrm{~cm})$, but the dryness index indicates slightly more dryness in $1997(-1.9)$ than in $1996(-1.8)$. This fact causes the correlations between the flux and the dryness index as shown in Figure 3 to be about 0.65 while it is only 0.34 between flux and average water levels (both calculations do not include the anomalous fields in 1996 and are statistically significant at $\mathrm{p}<0.01$ ). Curiously, the index does not involve the water levels themselves. We think the connection between methane emissions and water levels is an "on-off" relationship that is better represented by the index. Previous work at Tuzu also suggested that once the fields are inundated, the increased water depth does not further increase emissions. This is also seen in the last two years of the data here (1998 and 1999).

[25] It is apparent from the discussion that there is considerable spatial and temporal variability of emissions

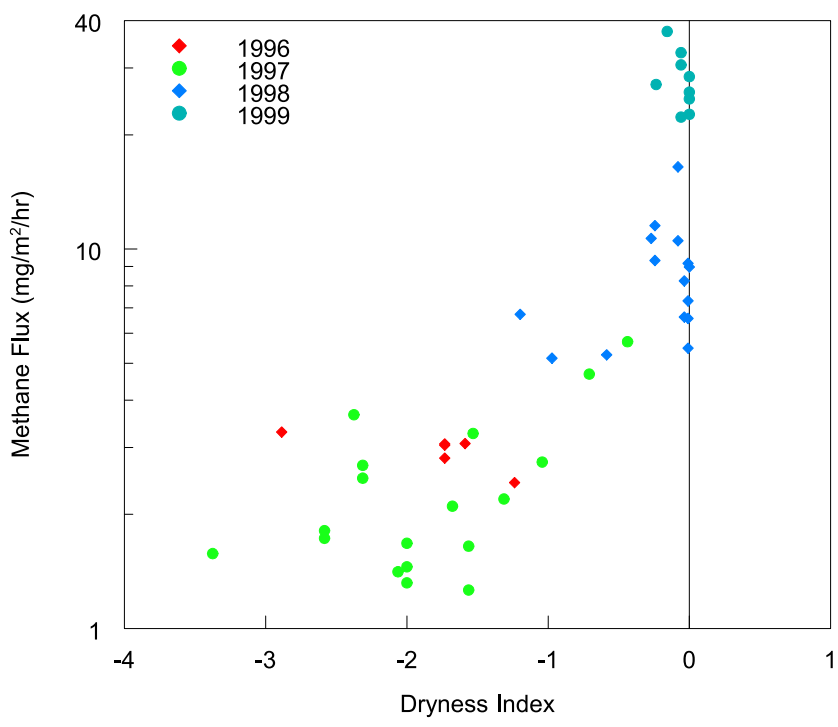

Figure 4. The effect of water management on methane emissions. The dryness index reflects the frequency and duration of intermittent flooding which affects methane emissions In the first 3 years, water availability has a major effect on emissions. In the last year, higher organic inputs further increase emissions. 


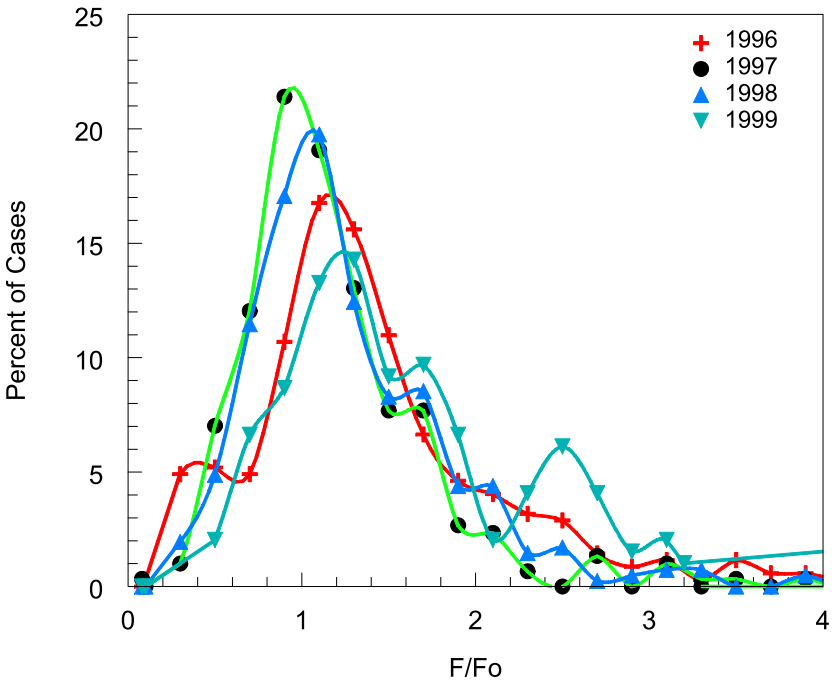

Figure 5. The frequency distribution of the ratio of afternoon to morning fluxes of methane from rice fields. The distributions have been normalized to 100 for comparisons of data from different years.

as well as the factors that cause methane to be produced and emitted from rice fields. We quantified the spatial variability by two methods. The first was to calculate the correlation coefficients between the time series of flux measurements of each plot with every other plot during the same year. The average correlations of the plots within the same field were $0.85,0.75,0.69$ and 0.40 for the years 1996 to 1999 (p < $0.01)$. The average correlations across fields were 0.36 , $0.55,0.31$ and 0.34 for the same years $(\mathrm{p}<0.01)$. When the fluxes are low there tends to be more coherence among plots and even plots across fields, but when the fluxes are high so is the spatial variability. In addition to the correlations a useful measure of the variability is the range of the seasonally averaged emissions measured in the various plots. We calculated the ratio of the maximum to minimum seasonally averaged emissions observed among the plots. From 1996-1999, the ratios were 1.4 (10), 4.5, 3.2 and 1.7 where the factor of 10 in the first year arises if we include the anomalous fields discussed earlier. In the second year the fluxes are so low that the ratio can easily become large without being a significant issue. In the last two years however, we see that single plots can differ from each other by factors of 2-3. If we consider the larger spatial units of the whole field, the results are in better agreement as would be expected. For 1996 the two fields left after excluding the anomalous fields have nearly the same emissions. The fields in 1997, with very low emission rates are still different by a factor of about 3 . In the last 2 years when the emissions are higher, the fields differ by a factor of 1.8 for 1998 and 1.3 for 1999 [see also Khalil et al., 1998a].

\section{Factors Related to Emissions}

[26] We have already considered the major factors that directly affect methane emissions, namely the organic material supplied to fields as fertilizer or crop residues and the management of water. A large number of other factors were also observed, some of which either directly affect methane emissions or are indicators of the emissions from the rice fields and may be useful proxies.

[27] We will discuss several experiments here that are of scientific interest to study in the field. First we measured emissions from plots in the fields with no plants to quantify the role of the rice plant in the emission of methane to the atmosphere; second, we wanted to quantify the possible diurnal cycle of emissions, if any; and third, we took background air measurements of methane near the fields as a potential proxy of emissions. As mentioned earlier, we also took measurements of environmental conditions such as soil and air temperatures, wind, cloudiness, $\mathrm{pH}$ and Eh. The results of these will not be discussed further in this paper, but the data are included in the auxiliary material.

[28] To observe the effect of plants on methane emissions we conducted experiments on one plot with no plants in each of the 6 fields during 1997. We found that if we applied our usual criteria of rejecting measurements that failed to show linear accumulation by the $r^{2}>0.9$ criteria, almost all the measurements had to be rejected while for the experiments with plants the rejection rate is only a few percent. In fields $1-6$ the number of acceptable cases out of 53 days of sampling were $1,6,8,8,5$ and 17 ; for these cases the average emissions found were $0.7,0.7,1,1,4$ and $6.4 \mathrm{mg} / \mathrm{m}^{2} / \mathrm{hr}$ respectively, which when taken as an average for the growing season come out to be $0,0.1,0.2,0.2,0.4$ and $2 \mathrm{mg} / \mathrm{m}^{2} / \mathrm{hr}$ for fields $1-6$ and would constitute $10 \%$ or less of the emissions from the fields except for field 6 . Here of the 17 cases, two show quite high fluxes of 40 and $46 \mathrm{mg} / \mathrm{m}^{2} / \mathrm{hr}$ - rates that were not observed even in any of the more than 300 cases studied with plants. If these two are eliminated the seasonal value comes down to about $0.8 \mathrm{mg} / \mathrm{m}^{2} / \mathrm{hr}$ or also about $10 \%$ of the seasonal average emissions from plots with plants in this field. Such studies were only conducted in 1997 when the fluxes turned out to be the lowest of the 4 years. Nonetheless, we conclude that there was little flux from the regions with no plants, perhaps only about $10 \%$.

[29] The diurnal cycle, if any, is of interest both from the point of view of understanding the mechanics of methane production and its controlling factors as well as designing measurement programs for field sampling. Although logistical constraints prevented detailed temporal measurements we took samples at the extremes of the day's temperature and environmental conditions by sampling during the mornings and the afternoons. Specifically at around 9:00 and then 12:00 of the next day during 1996, alternating between early morning (7:00), noon, early and late afternoons in 1997, and 7:00-9:00 in the mornings and 3:005:00 in the afternoons of each day of sampling for 1998 and 1999.

[30] It is instructive to look at the frequency distributions of the ratios of afternoon to morning fluxes $\left(\mathrm{F} / \mathrm{F}_{0}\right)$ as shown in Figure 5. The modal values of this ratio are 1.1, 0.9, 1.1 and 1.3 for the years from 1996-1999 and the median values are a little higher at 1.3,1.1, 1.2 and 1.4. This result is somewhat surprising as it suggests $10 \%-40 \%$ higher emissions during the afternoon compared with the mornings. The response is least during 1997 when the overall fluxes are also the smallest, while it is highest in 1999 when the fluxes were largest. Moreover, in 1999 some $20 \%$ of the cases show fluxes between 2-3 times higher in the after- 


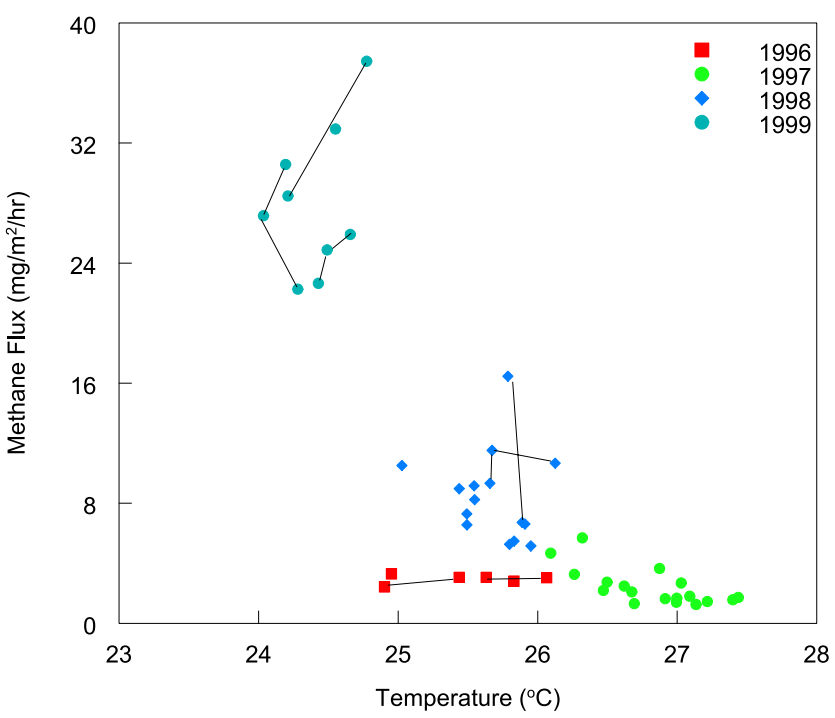

Figure 6. The relationship between methane flux and soil temperature for the years 1996-1999. The result shows that while higher soil temperatures generally raise the flux, other factors can overwhelm this effect.

noon compared with the mornings, although the total number of cases for this year is only about 200 while for the other years there were $300-400$ total valid cases. In the present study and in our other studies we have taken samples at different times of the day to insure against a bias from the time of day and it seems to be a necessary condition for obtaining accurate seasonally averaged results.

[31] The causes of these variations by time of day remain somewhat mysterious. Since the production takes place at $5-15 \mathrm{~cm}$ below the surface it is not affected directly by light, nor are the bacteria that produce methane. At $5 \mathrm{~cm}$, where we took measurements, soil temperature changes 3 $4^{\circ} \mathrm{C}$ between the morning and afternoon sampling times and it is fairly consistent from year to year. Moreover, there are significant time lags between production and emission as methane is transported upwards thus making it difficult to connect this temperature change with the additional flux. Yet for higher temperatures, both the plant respiration and ebullition may change and could contribute to the observations.

[32] Generally higher soil temperatures are expected to increase methane emissions although in our work the overall relationship between the seasonally averaged flux and similarly averaged soil temperature is negative as shown in Figure 6. These results do not contradict the expectation of higher emissions with increased temperature, but show that other factors that control methane emissions can easily overwhelm the effect of temperature. This is partly because the temperature does not change much from year to year in the same location. In our studies for example, the variation of annual mean soil temperature during the growing season is only about $3{ }^{\circ} \mathrm{C}$. We have included this figure to further confirm the dryer and hot conditions of 1997 (the highest soil temperatures of around $27^{\circ} \mathrm{C}$ ) and in 1999 we see the lowest soil temperatures (about $24^{\circ} \mathrm{C}$ ). In 1996 the seasonally averaged soil temperatures are in the middle of the range for the four years of experiments and once again do not explain why the anomalous fields produced more methane than the other two. The variation of seasonally averaged soil temperature within a field based on the measurements in each plot is $0.1-0.5^{\circ} \mathrm{C}$. Across fields the range of average temperature during the same year is $<1^{\circ} \mathrm{C}$ except for the first year when it is $\sim 1.8^{\circ} \mathrm{C}$. The causes of such variations are not known but may be shading by trees or topography, although the area is flat and extensively devoted to rice agriculture. Air temperatures were also measured and the seasonal averages were close to those for the soil temperatures with a similar inter-annual pattern of highest temperature in 1997 and lowest in 1999 with the other two years in the middle.

[33] The background concentrations of methane near the rice fields are expected to reflect the emissions. In our previous study at nearby Tuzu the relationship between measured fluxes and the concentration near the fields was good enough to use is as a proxy for emissions [Khalil and Rasmussen, 1998]. A strong relationship between flux and background concentrations is needed if remote sensing is to be used to determine emissions from rice fields. It is also possible to use these ambient concentrations and combine them with meteorological data to estimate the large scale emissions of methane from rice fields using small scale and regional dispersion models. The background samples were taken in triplicate next to each of the fields along the dividers between fields and at about $2 \mathrm{~m}$ height. These are averaged to obtain a background concentration for each field for each time of sampling. We show the relationship between the seasonally averaged background concentrations (equation (3)) and the flux in Figure 7. There is a generally positive correlation as would be expected. In 1999 it even appears that the field that had lower emissions had a smaller background concentration. During this year the emissions were quite high so the variations would be more easily detectable in the background concentration. The background concentrations near the fields in 1996 were 2450,

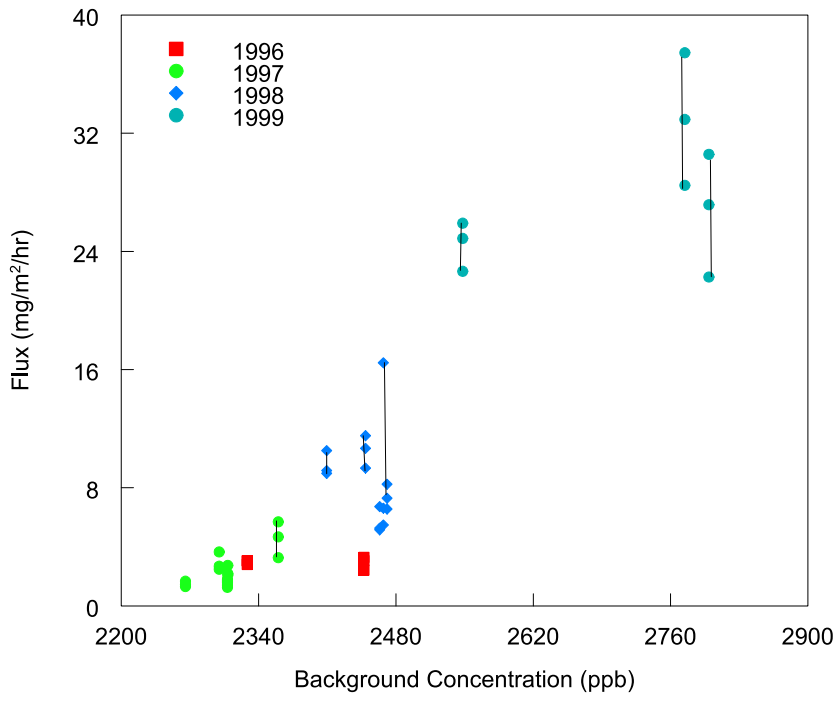

Figure 7. Seasonally averaged background concentrations of methane near fields where flux measurements were taken for each of the years from 1996 to 1999 and the fluxes measured. 
2440, 2330, 2230 and $2250 \mathrm{ppb}$ for fields $1-5$ of which fields 2, 4 and 5 had anomalously high emissions (not shown in Figure 7). We see that the background concentrations do not support the high emission rate, although as mentioned earlier, we do not have any direct indicator that the measurements are inaccurate.

[34] The background measurements taken during the morning and the afternoon show markedly different concentrations. We attribute this to the changes in the diurnal boundary layer. As would be expected from this mechanism, concentrations are high in the morning reflecting the nighttime emissions that build up in a shallow mixing layer. We have seen that the emissions are generally higher in the afternoon compared with the morning, yet the background concentration is lower because the mixing layer is much higher, thus diluting the flux from the rice fields. These results are very consistent from year to year as shown in Figure 8 . We see also that the time of day difference in the background concentration is much larger when the fluxes are large as in the later years 1998 and 1999.

\section{Production and Oxidation}

[35] Having already introduced the relationships between methane production, oxidation and emissions, we now complete the picture created by our experiments. The production measurements were very time consuming and so could only be carried out at a relatively low temporal frequency and were taken only during 1998 and 1999 after the site had been established and the facilities could be set up. To show the results, we first want to explain how we calculated the appropriate variables from the measurements so that they can connect with the flux measurements already discussed.

[36] The auger provides samples at depths about $2.5 \mathrm{~cm}$ apart down to the bottom of the tilled layer. From these samples we determine the production rate $\mathrm{P}_{\mathrm{o}}(\mathrm{z}, \mathrm{t})$ in $\mathrm{mg}$ $\left(\mathrm{CH}_{4}\right) / \mathrm{cm}^{3}$ (paddy soil)/hr at specific locations $\mathrm{z}$ in the vertical and times during the growing season $(t)$. We divide the tilled soil of total depth $\delta \approx 15-20 \mathrm{~cm}$ into horizontal slabs about $2.5 \mathrm{~cm}$ thick with boundaries determined by the locations where we took the soil samples. For each slab then, we have a production measurement on the top and the bottom. We calculate the production per square meter of the slab as:

$$
\mathrm{P}\left(\mathrm{z}+1 / 2 \delta_{\mathrm{o}}, \mathrm{t}\right)=1 / 2\left[\mathrm{P}_{\mathrm{o}}(\mathrm{z}, \mathrm{t})+\mathrm{P}_{\mathrm{o}}\left(\mathrm{z}+\delta_{\mathrm{o}}, \mathrm{t}\right)\right] \delta_{\mathrm{o}}
$$

Here $\mathrm{z}$ is the depth $(\mathrm{m}), \mathrm{P}_{\mathrm{o}}(\mathrm{z}, \mathrm{t})$ is the measured production in $\mathrm{mg} / \mathrm{m}^{3} / \mathrm{hr}$ at the location $\mathrm{z}$ at one boundary of the slab in question, and similarly $\mathrm{P}_{\mathrm{o}}\left(\mathrm{z}+\delta_{\mathrm{o}}, \mathrm{t}\right)$ is the measured production at the lower boundary of the same slab at the same time and $\delta_{\mathrm{o}}$ is the slab thickness $(\sim 2.5 \mathrm{~cm})$. The quantity we report, that can be compared with the flux, is the production $\mathrm{P}\left(\mathrm{z}+{ }^{1} / 2 \delta_{\mathrm{o}}, \mathrm{t}\right)$ in $\mathrm{mg} / \mathrm{m}^{2} / \mathrm{hr}$ at the center of the slab $\left(\right.$ at $z+1 / 2 \delta_{\mathrm{o}}$ ) for each time of sampling $t$ as calculated by equation (5). This gives us the production in each slab from the top to the bottom of the tilled layer. We assume that the production rates are zero at the top surface of the topmost slab and the bottom surface of the deepest slab.
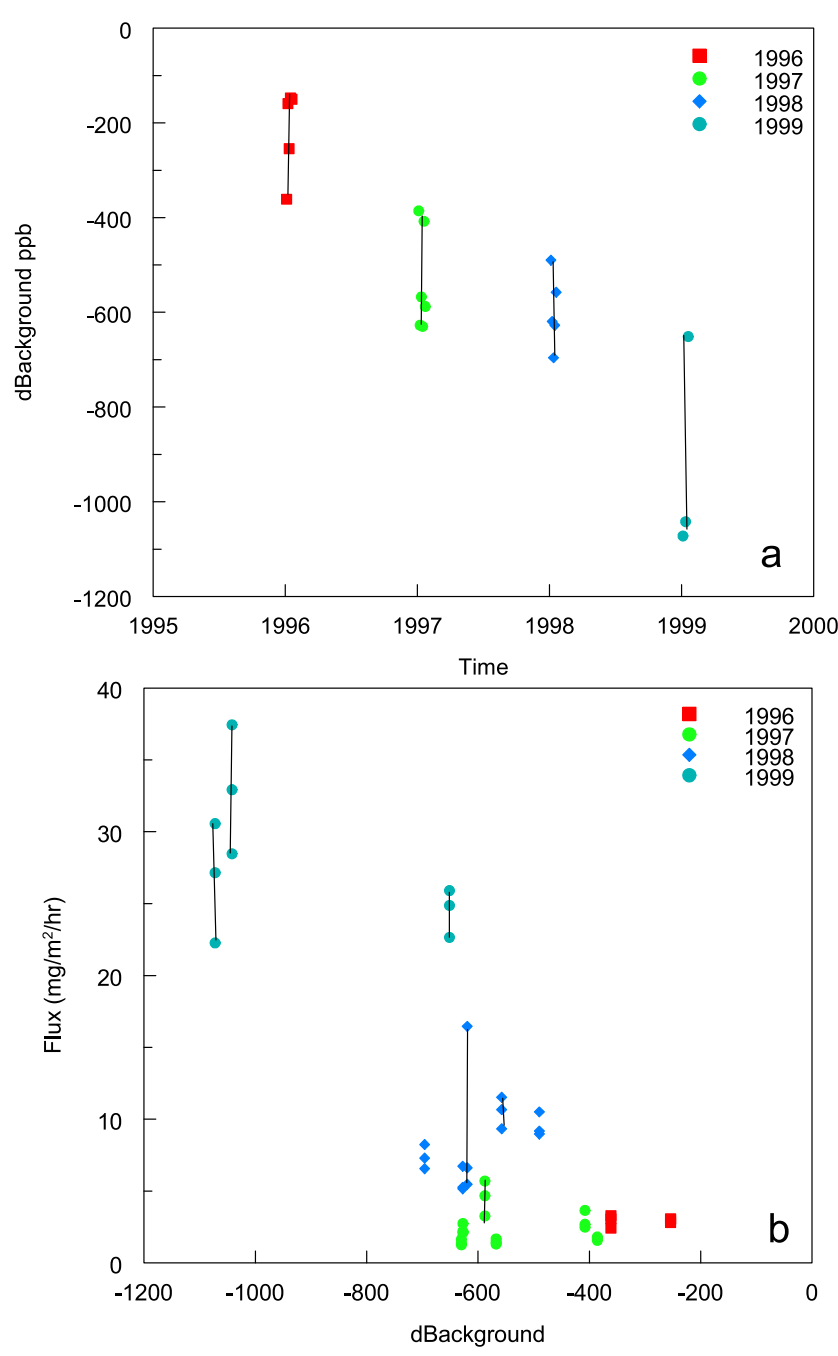

Figure 8. (a) The difference of methane concentrations between afternoon and morning, near rice fields in Jinsha, Sichuan, China. (b) The relationship between methane flux and the change of background concentration of methane during the day.

[37] We can form three integrated quantities that fully describe the results of the production measurements: $\mathrm{P}(\mathrm{z})=$ $(1 / \mathrm{T}) \int \mathrm{P}(\mathrm{z}, \mathrm{t}) \mathrm{dt}, \mathrm{P}(\mathrm{t})=(1 / \delta) \int \mathrm{P}(\mathrm{z}, \mathrm{t}) \mathrm{dz}$ and $\mathrm{P}=(1 / \mathrm{T} \delta) \iint$ $\mathrm{P}(\mathrm{z}, \mathrm{t}) \mathrm{dz} d \mathrm{~d}$. The first is the seasonally average "depth profile" obtained by using equation (3). The second is the average production rate in the tilled layer as a function of time during the growing season and is obtained by a slightly modified form of equation (3) where the time is exchanged for spatial measurements and the last variable is perhaps the most informative giving us the average production of methane per square meter of soil per hour during the growing season. The depth profiles are shown in Figure 9. We have also averaged over the three plots sampled in each field to produce this figure. There is a high correlation among the plots of each field. For 1998 the average correlations of $\mathrm{P}(\mathrm{z})$ were $0.85,0.91$ and 0.83 for the three plots in each of the fields 1,2 and $3(\mathrm{p}<0.01)$. For 1999, the correlations were 0.90 or higher for plots in fields 1,3 and $5(\mathrm{p}<0.01)$. Moreover we see that the results are very 


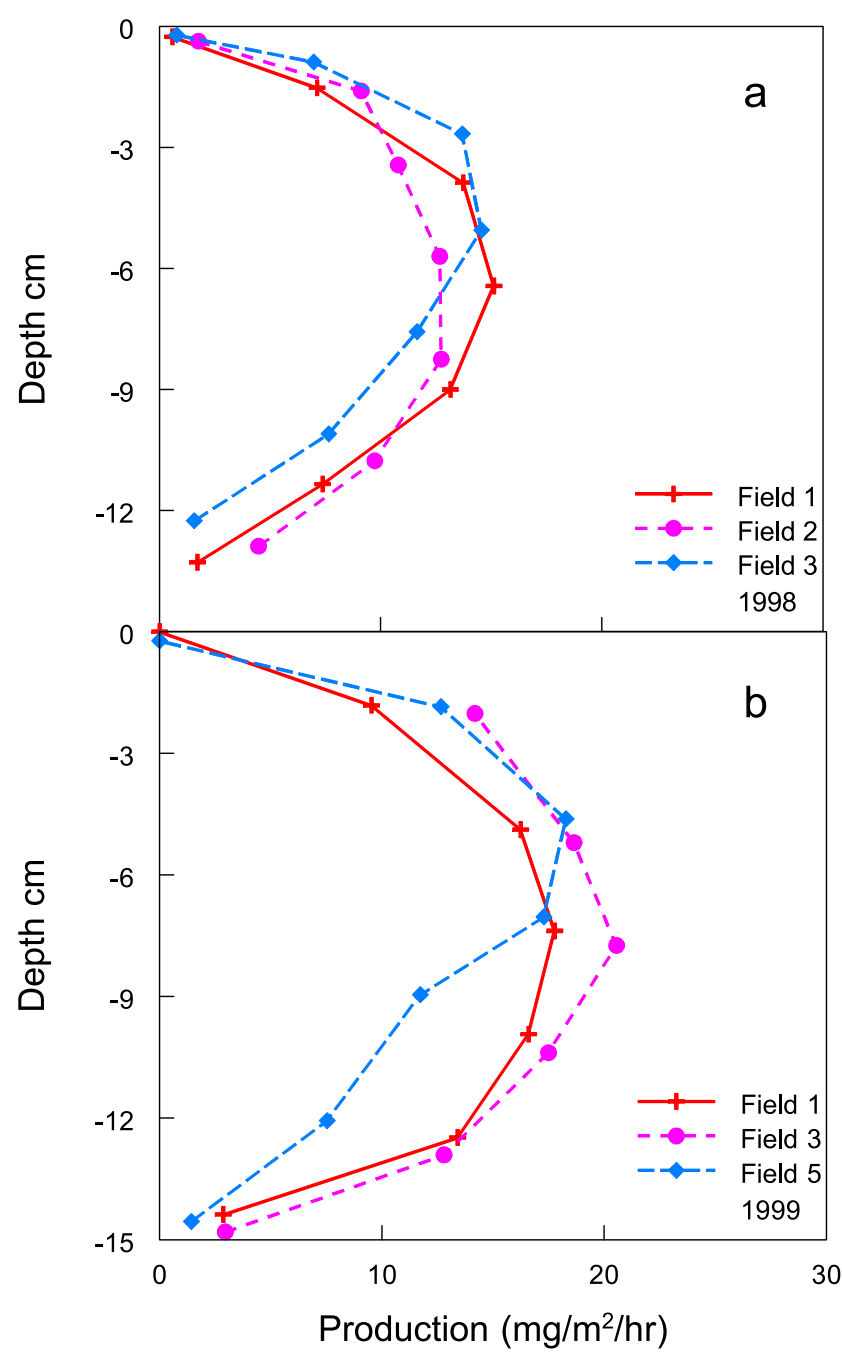

Figure 9. The seasonally averaged production of methane in the tilled layer of the rice fields in Jinsha, Sichuan, China for 1998 and 1999. In each year, samples were taken in three plots in each of three fields.

consistent among the fields during each of the two years when such measurements were taken. The average correlation between the fields for 1998 were 0.96 and for 1999 the average was 0.94 . It should be noted that although the correlation coefficients are encouragingly high, because of the small number of measurements involved, the uncertainties in these coefficients are also quite high. For $r=0.9$ the lower $90 \%$ confidence limit is about 0.6 . An inspection of the figure shows that the maximum production takes place between 5 and $10 \mathrm{~cm}$, at least in this study.

[38] The time variation of the production is described by $\mathrm{P}(\mathrm{t})$ defined above and is shown in Figure 10 for each of the two years averaged over all fields. For comparison, the emissions measured at the same time as the production are also shown.

[39] The temporal relationship between production and emission is quite complicated. The production that is measured at one time has an effect on emissions at a later time. This is because it takes time for the methane to be transported to the root zone, where some of it is oxidized and the rest is further delayed by the transport barrier between the soil and the root into which the methane must penetrate before it can follow the conduits in the plant towards the release to the atmosphere. These delays generally cause a lack of direct relationship between production and flux. In 1998 the correlations for the fluxes and production averaged over the plots were $0.8,0.1$ and 0.6 for fields 1, 2 and 3 and for 1999 the correlations were 0.3, 0 and 0.2 for fields 1,3 and 5 respectively. The higher correlations in some cases are due to the fact that both the production and flux are increasing for quite a long time between 30 and 80 days after transplanting. This causes a high correlation even though the flux measured at one time is due to production at some earlier time. It is noteworthy that the pattern of the flux and production is not the same during the growing season. The flux starts to fall off earlier than the production. This may be due to changes in the oxidation rate during the growing season. Finally, the seasonally averaged production rate $(\mathrm{P})$ for each plot sampled was found to range from 50 to $80 \mathrm{mg} / \mathrm{m}^{2} / \mathrm{h}$ (specifically the production was calculated in $\mathrm{mg} / \mathrm{m}^{2} / \mathrm{h}$ to be as follows: 1998, Field 1, Plots 1-3: 58, 53 and 57; Field 2, 84, 52, 50, Field 3: 50, 67, 62; for 1999, Field 1, Plots $1-3$ it was 74 , 129, 102; Field 3: 79, 77, 194 and Field 5: 55, 69, 83).

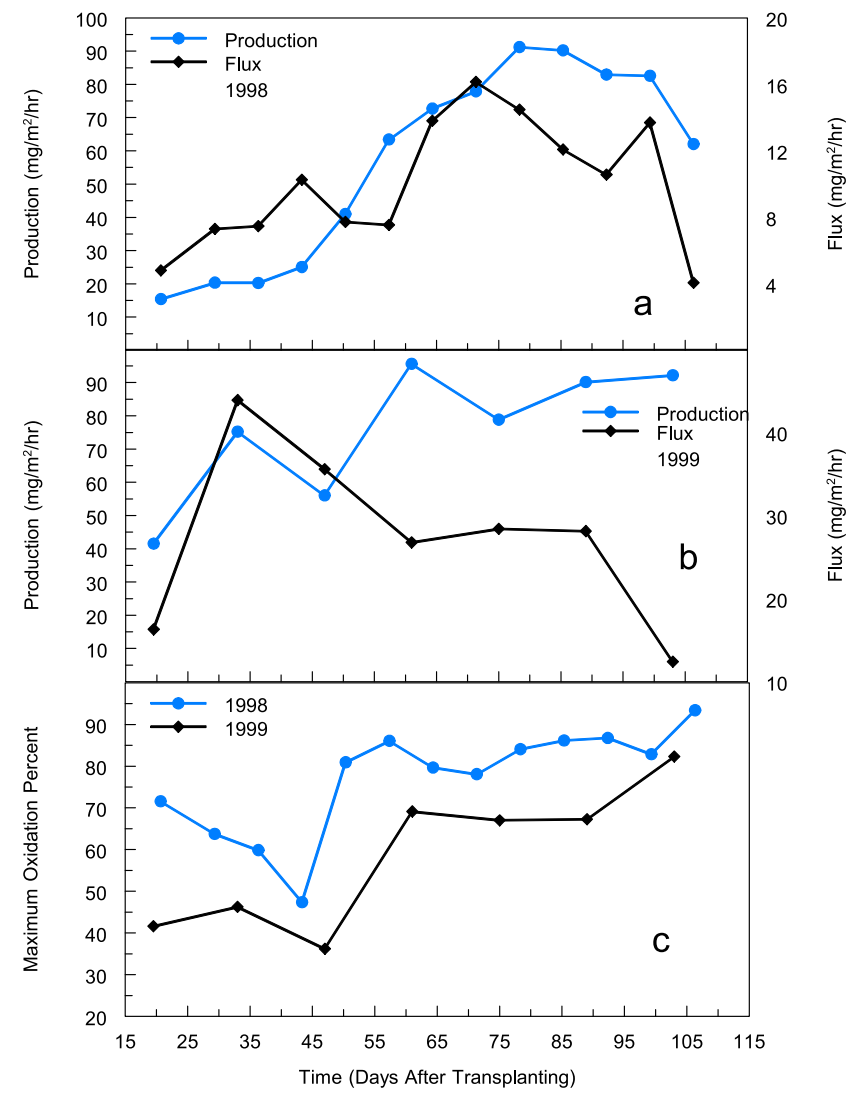

Figure 10. The production of methane in rice fields (Jinsha, Sichuan, China), during the growing season. The first two panels show the production rates along with fluxes measured at the same time for comparison. The third panel shows the maximum calculated oxidation percent during the same time. The actual oxidation rate at these times is expected to be somewhat lower. 


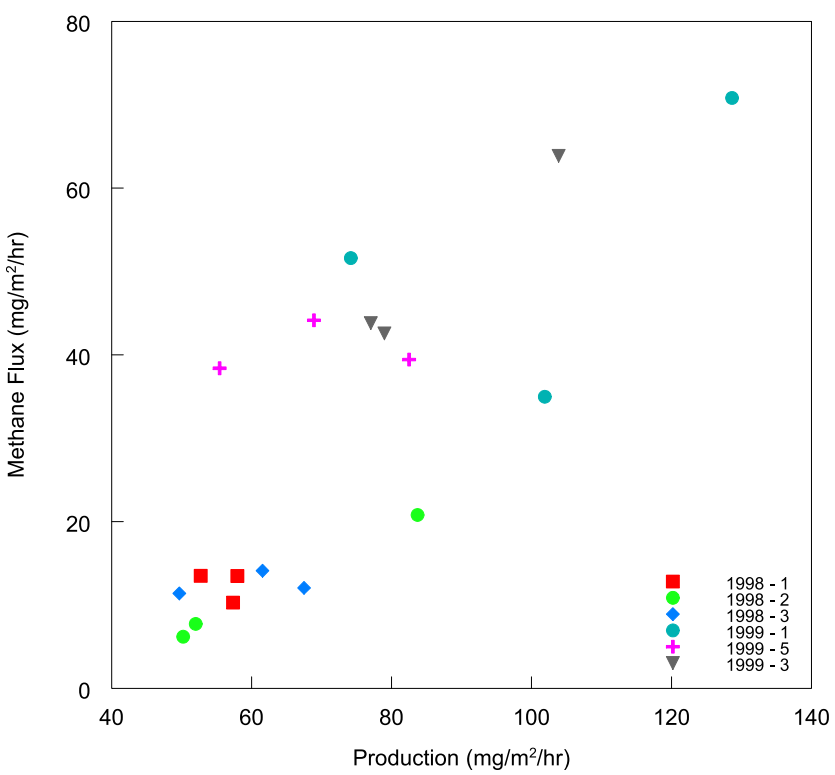

Figure 11. The relationship between seasonally averaged production and emissions of methane from rice fields at Jinsha, Sichuan, China.

[40] We can now discuss the final element in the mass balance: oxidation, as introduced in equations (1) and (2). The lack of pore water concentration measurements makes it difficult to calculate the oxidation rate during the growing season based on our data. The amount of methane that is produced at any given time is balanced by the amount that is being oxidized, the amount being released (flux) and the amount stored in the pore water (equation (1)). If we assume that the stored amount is small at any time compared with the production rates or $(\mathrm{dC} \delta / \mathrm{dt}) \ll \mathrm{P}$ in equation (1), then we can calculate the fraction oxidized according to this equation and the results are as shown in Figure 10. We consider this to be the upper limit of the oxidation rate during the growing season and generally shows a increasing tendency as the season progresses. This is consistent with the expectation that the methane production processes have to deliver substantial amounts of methane before the certain methanotrophic bacteria can grow and utilize it so that towards the later stages of growth most of the methane produced is oxidized. If we integrate equation (1) over the entire growing season, the contribution of the stored amount becomes negligible. Integrating equation (1) and dividing by the length of the growing season gives us: $[\mathrm{C}(\mathrm{T}) \delta-$ $\mathrm{C}(0) \delta]=\mathrm{P}_{\mathrm{TOT}}-\Phi_{\mathrm{TOT}}-\mathrm{Ox}_{\mathrm{TOT}}$, where the variables on the right hand side are the total production, flux and oxidation per square meter during the growing season. The total production is much greater than the terms on the left hand side, which can therefore be ignored. For the seasonal averages therefore, the fraction oxidized can be written as $\mathrm{f}=[1-<\Phi>/ \mathrm{P}]$. For all variables $\mathrm{X}_{\mathrm{TOT}}=<\mathrm{X}>\mathrm{T}$, where $\mathrm{T}$ is the length of the growing season. The calculated values of $\mathrm{f}$ in percent are: For 1998, Field 1, Plots 1-3: $\mathrm{f}=77,74,82$; Field 2: 75, 85, 88; Field 3: 77, 82, 77; for 1999, Field 1: 30, 45, 66; Field 3: 46, 43, 39 and Field 5: 31, 36, 52. The integration of equation (1) over the growing season shows that $\langle\Phi\rangle=\mathrm{P}-<\mathrm{Ox}>$ and we expect that $\langle\mathrm{Ox}\rangle$ is proportional to $\mathrm{P}$ so that $\langle\Phi\rangle=(1-\mathrm{f}) \mathrm{P}$ which suggests that the seasonally averaged fluxes and production rates should be proportional even if such a relationship does not exist for each time of measurement. Figure 11 confirms this relationship for the present study.

[41] The results show that the fraction oxidized was $\sim 80 \%$ in 1998 and only $\sim 43 \%$ in 1999 . The reasons for such differences are not known, but we suspect that when there is an overabundance of organic matter in the fields the oxidized fraction is less. This was also seen in the studies at near by Tuzu. At Tuzu there was a continual saturated supply of organic material and oxidation rates were estimated at about 60\% [Khalil et al., 1998b].

[42] There is considerable variability in the average production and oxidation rates at the spatial level of the plots. Production varies from $50-90 \mathrm{mg} / \mathrm{m}^{2} / \mathrm{hr}$ in 1998 and from $60-130 \mathrm{mg} / \mathrm{m}^{2} / \mathrm{hr}$ in 1999 (in rounded numbers); oxidation varies from $70 \%-90 \%$ in 1998 and $30 \%-70 \%$ in 1999 (again in rounded numbers). At the spatial level of a field, the variability is much less at only about $20 \%$. Our results show that the major reason for the increase of emissions between 1998 and 1999 must be the change of oxidation since the production goes from an average of about $60 \mathrm{mg} / \mathrm{m}^{2} / \mathrm{hr}$ to about $90 \mathrm{mg} / \mathrm{m}^{2} / \mathrm{hr}$. If the oxidation rate had remained at $80 \%$ in 1999 the flux should have changed only from 12 to $18 \mathrm{mg} / \mathrm{m}^{2} / \mathrm{hr}$, but instead it went to an average of $30 \mathrm{mg} / \mathrm{m}^{2} / \mathrm{hr}$. Of course the oxidation is not directly measured, so it is a conclusion on our part to say that the major reason for the increase of emissions from 1998 to 1999 is due to oxidation, because the measured production rates can only account for a small change. There are not many other credible possibilities.

\section{Discussion and Conclusions}

[43] In our research at Jinsha we found that the prevailing agricultural practices were to use nitrogen fertilizers with an intermittent supply of water. Under these conditions the fluxes measured were $\sim 3 \mathrm{mg} / \mathrm{m}^{2} / \mathrm{hr}$. In the subsequent years as we supplied more water and saturated levels of organic material, the fluxes went up to $30 \mathrm{mg} / \mathrm{m}^{2} / \mathrm{hr}$, which are about the same as the emissions we had measured in our earlier work at nearby Tuzu. At Tuzu however, the prevailing agricultural practices were quite different and included continuously flooded fields and abundant supply of organic material, some from crop residues, but also from farm compost and sludge from biogas generators.

[44] Although the major factors such as water management and fertilizers produce consistent results, spatial or replicate variability remains large and inexplicable. When considering individual plots during the same year, the average emissions ranged over a factor of 3 , but when we take the fields as a whole, the range is at most 1.8. Such small scale variability introduces one of the many difficulties of extrapolating field measurements to regional and country-wide emissions.

[45] Production measurements add considerably to our understanding of the processes and the nature of the variability. In our experiments, the seasonally averaged production and emissions are well correlated. More interestingly however, it seems that when more organic material was available, as in the last year, the production did not 
increase greatly, but the flux did. This result suggests that the oxidation rate may have been suppressed in the presence of large amounts of organic material. These findings are consistent with earlier work at Tuzu, which also showed reduced oxidation, and the result that after a certain amount, additional organic material does not lead to more emissions.

[46] During the course of these experiments we also conducted interviews with farmers from many different villages well beyond the areas of our experiments. Although it is still difficult to quantify the results, we found uniform evidence that nitrogen fertilizers are being used more and more on the rice fields replacing organic amendments. Moreover, there is a growing lack of water and fields are rarely kept inundated for the whole growing season although there is enough water to keep the soils moist, if not saturated. After the rice canopy shades the soil, standing water is often not present. Under these conditions the methane fluxes fall to low levels well before the harvest of the rice crop. The studies we have reported here and at Tuzu are indicators of the large scale changes that are occurring in rice agriculture in China as it relates to methane, and possibly nitrous oxide emissions. These trends reduce the emissions factors for methane from rice fields in China. Moreover, the area of rice harvested has also been declining in China. This is due to the abandonment of marginal land that had been cultivated to meet earlier governmental demands. Additionally, in many areas of China, farmers are growing other crops in their fields instead of multiple crops of rice each year. The use of faster growing and high yielding hybrid rice varieties is further reducing the areas harvested and the time of the year taken by rice agriculture. Since both the annual area of rice harvested and the emissions of methane per hectare of rice grown have been decreasing we have estimated in our recent paper that during the last 20 years methane emissions from rice fields in China have fallen considerably from high rates of some $30 \mathrm{Tg} / \mathrm{yr}$ to present rates of perhaps around 8$10 \mathrm{Tg} / \mathrm{yr}$ [Khalil and Shearer, 2006; Li et al., 2002]. Similar factors may also be reducing methane emissions from rice fields world-wide.

[47] Acknowledgments. We thank Christopher Butenhoff and Zhengqin Xiong at PSU for discussions. This work was supported by the Office of Science (BER), U.S. Department of Energy, grants DE-FG0397ER62401 and DE-FG02-04ER63913. Additional support was provided by the resources of the Biospherics Research Corporation and the Andarz Co.

\section{References}

Aulakh, M. S., J. Bodenbender, R. Wassmann, and H. Rennenberg (2000a), Methane transport capacity of rice plants. II. Variations among different cultivars and relationship with morphological characteristics, Nutr. Cycling Agroecosyst., 58, 367-375.

Aulakh, M. S., R. Wassmann, H. Rennenberg, and S. Fink (2000b), Pattern and amount of aerenchyma relate to variable methane transport capacity of different rice cultivars, Plant Biol., 2, 182-194.

Barker, R., T. P. Tuong, Y. Li, E. G. Castillo, and B. A. M. Bouman (2004), Growing more rice with less water: Research findings from a study in China, Preface to a special issue, Paddy Water Environ, 2, 185.
Boone, D. (2000), Biological formation and consumption of methane, in Atmospheric Methane, Its Role in the Global Environment, edited by M. A. K. Khalil, pp. 42-62, Springer, Berlin.

Chanton, J. P., and J. W. H. Dacey (1991), Effects of vegetation on methane flux, reservoirs, and carbon isotopic composition, in Trace Gas Emissions by Plants, edited by T. D. Sharkey, E. A. Holland, and H. A. Mooney, pp. 65-92, Academic, San Diego, Calif.

Denier van der Gon, H. A. C., and N. van Breemen (1993), Diffusioncontrolled transport of methane from soil to atmosphere as mediated by rice plants, Biogeochemistry, 21, 177-190.

Eller, G., and P. Frenzel (2001), Changes in activity and community structure of methane oxidizing bacteria over the growth period of rice, Appl. Environ. Microbiol., 67, 2395-2403.

Holzapfel-Pschorn, A., R. Conrad, and W. Seiler (1986), Effects of vegetation on the emission of methane from submerged paddy soil, Plant Soil, $92,223-233$.

Khalil, M. A. K., and R. A. Rasmussen (1998), Using ambient concentrations as proxy for methane flux measurements from rice fields, Chemosphere, 37(6), 1197-1205.

Khalil, M. A. K., and M. J. Shearer (2006), Decreasing emissions of methane from rice agriculture, in Greenhouse Gases and Animal Agriculture: An Update, Int. Congress Ser., 1293, 33-41.

Khalil, M. A. K., R. A. Rasmussen, M. J. Shearer, R. W. Dalluge, L. X. Ren, and C.-L. Duan (1998a), Measurements of methane from rice fields in China, J. Geophys. Res., 103(D19), 25,181-25,210.

Khalil, M. A. K., R. A. Rasmussen, and M. J. Shearer (1998b), Effects of production and oxidation processes on methane emissions from rice fields, J. Geophys. Res., 103(D19), 25,233-25,239.

Krüger, M., P. Frenzel, and R. Conrad (2001), Microbial processes influencing methane emission from rice fields, Global Change Biol., 7, 49-63.

Krüger, M., G. Eller, R. Conrad, and P. Frenzel (2002), Seasonal variation in pathways of $\mathrm{CH}_{4}$ production and in $\mathrm{CH}_{4}$ oxidation in rice fields determined by stable carbon isotope and specific inhibitors, Global Change Biol., 8, 265-280.

Li, C., J. Qiu, S. Frolking, X. Xiao, W. Salas, B. Moore III, S. Boles, Y. Huang, and R. Sass (2002), Reduced methane emissions from largescale changes in water management of China's rice paddies during 1980 2000, Geophys. Res. Lett., 29(20), 1972, doi:10.1029/2002GL015370.

Masscheleyn, P. H., R. D. Delaune, and W. H. Patrick Jr. (1993), Methane and nitrous oxide emissions from laboratory measurements of rice soil suspension: Effect of soil oxidation-reduction status, Chemosphere, $26(1-4), 251-260$

Neue, H.-U., and P. A. Roger (2000), Rice agriculture: Factors controlling emissions, in Atmospheric Methane, Its Role in the Global Environment, edited by M. A. K. Khalil, pp. 134-169, Springer, Berlin.

Nouchi, I., S. Mariko, and K. Aoki (1990), Mechanism of methane transport from the rhizosphere to the atmosphere through rice plants, Plant Physiol., 94, 59-66.

Schütz, H., W. Seiler, and R. Conrad (1989), Processes involved in formation and emission of methane in rice paddies, Biogeochemistry, 7, 33-53.

Shearer, M.J., and M. A. K. Khalil (1993), Rice agriculture: Emissions, in Atmospheric Methane: Sources, Sinks, and Role in Global Change, edited by M. A. K. Khalil, pp. 230-253, Springer, Berlin.

Shearer, M. J., and M. A. K. Khalil (2000), Rice agriculture: Emissions, in Atmospheric Methane, Its Role in the Global Environment, edited by M. A. K. Khalil, pp. 170-189, Springer, Berlin.

C. L. Duan, Institute of Mountain Disasters and the Environment, P.O Box 417, Chengdu, Sichuan 610041, China.

M. A. K. Khalil, Department of Physics, Portland State University, P.O. Box 751, Portland, OR 97207, USA. (khalilm@pdx.edu)

R. A. Rasmussen, Department of Environmental and Biomolecular Systems, Oregon Graduate Institute, Oregon Health and Sciences University, 20000 NW Walker Road, Beaverton, OR 97006, USA.

L. X. Ren, Institute of Atmospheric Physics, Chinese Academy of Sciences, Beijing 100029, China.

M. J. Shearer, Environmental Science and Resources Program, Portland State University, P.O. Box 751, Portland, OR 97207, USA. 